\title{
Menstrual management: a neglected aspect of hygiene
}

\section{interventions}

\author{
Abstract \\ Effective menstrual management is essential for the mental and physical well being of women. However, \\ many women in low income countries lack access to the materials and facilities required. They are thus \\ restricted in their activities whilst menstruating thus compromising their education, income, and domestic \\ responsibilities. This study describes the menstrual management challenges faced by women in an \\ emergency situation in Uganda. Fifty interviews and focus group discussions were conducted with women \\ from villages, IDP camps, and schools so that the menstrual management of the host population could be \\ compared with the IDPs. This study showed that in IDP camps there was a significant lack of materials \\ including soap, underpants and absorbing cloth, and facilities like latrines and bathing shelters. As a \\ consequence women in IDP camps suffer with poor health and diminished dignity. There is also a lack of \\ education about menstruation and reproductive health and practices are strongly influenced by cultural \\ taboos.
}

\section{Keywords}

Emergencies, hygiene; IDP camps; menstrual management; sanitation; Uganda

\section{Introduction}

Improvements in water quality and quantity, sanitation and hygiene practices have the potential to prevent at least $9 \%$ of the global disease burden (in disability adjusted life years) (Prüss-Ustün et al 2008). Menstrual hygiene is one aspect that needs to be improved and indeed this is starting to be recognized when designing sanitation programmes at both a global policy level (for example Gomez 2006, Ten 2007, Raralio and Ebo 2009) and by non-governmental organizations (NGOs) working in the field 
(IFRCRC 2010). Specific examples include Bharadwaj and Patkar (2004) and Mahon and Fernandes (2010) working in India, Ahmed and Yesmin (2008) working in Bangladesh, Lal et al (2007) working in IDP camps after the Pakistan earthquake. Menstrual management is mentioned in the UNHCR's Commitments to Refugee Women (UN High Commission for Refugees 2001) and in commonly used reference manuals like "Engineering in Emergencies" (Davis and Lambert 2002), but these only address menstruation briefly and whilst the importance of addressing the problem with sensitivity is stressed, no specific recommendations are made. The latest version of the Sphere guidelines (2011) now contains a number of specific recommendations and this has increased from previous editions. Sphere standards are internationally recognized sets of common principles and universal minimum standards in life-saving areas of humanitarian $\underline{\text { response. }}$

Ignoring women and girl's menstrual management needs may not only impact their health but also their usual daily activities, including education, income and domestic duties. For instance, an inability to manage menstruation in schools due to inadequate toilet and bathing facilities is cited as one of the top reasons for girls' absenteeism, typically leading to them falling behind with their studies and eventually dropping out altogether (Bharadwaj and Patkar 2004, WaterAid 2005, Ten 2007, Tearfund 2009, Erulkar et al 2010). As such, it is clear that improving menstrual management is key for attaining Millennium Development Goal 3: "Eliminate gender disparity in primary and secondary education, preferably by 2005 , and in all levels of education no later than 2015" which in this context overlaps with Millennium Development Goal 7, target 3 "Halve, by 2015, the proportion of the population without sustainable access to safe 
drinking water and basic sanitation.” (UN 2008). Good menstrual management relies on a supply of clean water for washing as well as adequate sanitation facilities for changing menstrual materials (Narayan et al 2001, Bharardwaj and Patkar 2004, Lal et al 2007, Ahmed and Yesmin 2008, Tearfund 2009, Mahon and Fernandes 2010, Fernandes 2010).

The impacts of poor menstrual hygiene on health are not extensively described in the medical literature. Leegaard (1984) found that Swedish women were significantly more likely to experience regular bouts of candidiasis if they used sanitary pads rather than tampons. She also observed a relationship between positive candidiasis swabs and "spot" washing (as opposed to using a bath or a shower), though this relationship was not significant. However, later publications (Geiger and Foxman 1987) and (Demba et al 2005) covering the US and Gambia respectively found no relationship between menstrual practices and candidiasis. In a study of Indian women, Singh et al (2001) linked reproductive tract infections more generally to poor menstrual hygiene (defined as an absent or dirty menstrual pad). Tchoudomirova et al (1998) linked urinary tract infections to sanitary pad as opposed to tampon use in Swedish women. Czerwinksi (1996), working in the US, found that regular washing of the genital area with soap and water is sufficient to prevent infection. None of these studies attempted to prove a link between using dirty sanitary towels and getting vaginal or urinary tract infections, although several authors who have studied menstrual management in low-income countries have postulated that the link exists (Ahmed and Yesmin 2008, WaterAid 2009, Fernandes 2010, Mahon and Fernandes 2010). 
Although research in the area of menstrual management in low-income countries has grown recently, it is principally focused on school girls (Narayan et al 2001, Bharadwaj and Patkar 2004, WaterAid 2005, 2009, Adhikan et al 2007, Ten 2007, Deo and Ghattargi 2005, Kirk and Sommer 2006, Dasgupta and Sarkar 2008, Anibue et al 2009, Dhingra et al 2009, Erulkar et al 2010, Sommer 2010, McMahon et al 2011, Thakre et al (2012) Kamaljit et al 2012, Shanbag et al 2012). There are only four studies published on menstrual management in mature women in low income countries, (Ahmed and Yesmin 2008, Fernandes 2010, Mahon and Fernandes 2010, Sommer 2012).

A review of academic and grey literature highlights that research into menstrual management in IDP (internally displaced persons) camps was been largely ignored until Sommer's 2012 review paper, and even this highlights the need for more case study evaluations. For example van Roenne et al (2010) describe in detail the formation and evolution of the Reproductive Health Group in Guinea where nurses and midwives who had been forced to escape the conflicts in Sierra Leone and Liberia provided reproductive health services to their fellow refugees. However, their services seemed to only include antenatal care, postnatal care, family planning and sexually transmitted infection care, with no mention of any assistance on menstrual management. There is only one further study that addresses the issue: a short article on bathing shelters erected in IDP camps following the Pakistan earthquake (Lal et al 2007). They consulted the women on how to build shelters that would facilitate good menstrual hygiene. The women requested that "menstruation units" for washing and drying their menstrual cloths should be included within the screened bathing blocks, so that no one would know that the women 
were entering the blocks for that purpose. Such blocks were subsequently constructed and received positive feedback.

Thus, there is a clear need for a study focussing on the menstrual management practices and perceived needs of women in IDP camps. This research compares menstrual management between women in IDP camps, neighbouring villages and schools in Katakwi district of Uganda. As the disaster had a slow onset, comparing IDP women and girls in the camps with non-IDP women and girls settled in the same area highlights the differences in menstrual management. There are four research focus themes: menstrual materials; menstrual management facilities; education about menstruation; and daily life during menstruation. By comparing women in IDP camps to women in neighbouring villages, it is possible to assess how living in camps provides additional menstrual management challenges, compared to women living in villages. With this enhanced understanding of the challenges girls and women face, the paper recommends suitable changes to sanitation programmes designed for emergency situations.

In order to make recommendations, it was necessary to understand how sanitation planning in emergency camps occurs. The ideal situation is described by Davis and Lambert (2002). At the operational field level, a sub-group is responsible for sanitation planning. This may include a government public health authority, UN agencies, NGOs, private sector members (such as construction or excavation contractors) and representatives of the affected community. This group meet regularly. The group identifies the resources that need to be mobilized to meet sanitation needs; plan and 
implement a response; and monitor and evaluate progress making adjustments to the programme if necessary. In order to carry out these tasks effectively, they need to collect information about people's sanitation needs and how they should be addressed. Techniques for collecting information include interviewing, brainstorming, direct observation, participatory mapping, ranking and questionnaires. For example, community members could be asked to rank latrine criteria (such as privacy, distance from home, ease of cleaning) so the most suitable latrine types can be selected.

\section{[Insert Figure 1]}

\section{Background and methodology}

The district of Katakwi in North East Uganda (see Figure 1 for location) was selected for the research because this region contained both villages and IDP camps in close proximity, enabling a comparison of menstrual management in different settings to be made. At the time of the research (2005 and 2006), Katakwi was affected by two ongoing conflicts. Firstly the area suffered from incursions by the Lord's Resistance Army (LRA), which had a record of murder, torture, rape and abduction. Secondly, there were violent attacks from neighbouring Karamoja. This started as cattle rustling, but in more recent times included rape and murder (International Displacement Monitoring Centre, 2005). All the camps had more women than men, with the proportion of women for individual camps ranging from $51 \%$ to $62 \%$. Lutheran World Federation (LWF) staff reported that this imbalance was caused by men being killed, 
abandoning their families or being away in the army or towns where they are seeking work.

The research took place over June and July 2005 and 2006 by two female researchers. Thirteen IDP camps were chosen in conjunction with LWF. They varied in size (from around 400 to 2000 people) and length of existence (two to five years). Levels of security in the camps also varied according to the LWF staff. Camps were selected from the north, south east and west parts of the district in order to give a representative view. Four villages and fourteen schools were selected due to their close proximity to the IDP camps. The rationale for selecting a range of camps with a variety of characteristics was to get a clear picture of the diversity of menstrual management challenges faced. Some of the newer or more insecure camps may not have experienced as much intervention on menstrual management from NGOs as the older or more secure camps. In smaller camps interventions may be more likely to filter to household level, conversely larger camps may attract the attention of more NGOs.

Since the research took place the situation has changed radically, and it became safe for the camps to be dispersed and people to return home.

This piece of research is primarily applied in nature, seeking to solve a particular problem, and began in an exploratory rather than descriptive or explanatory manner (Neuman, 1977), asking 'what are the differences between menstrual management in IDP camps, neighbouring villages and schools?' It then evolved into action research, treating 
knowledge as a form of power to empower and attempting to improve conditions (ibid) through making recommendations for design changes to sanitation programmes in Katakwi. Further recommendations based on wider principles appropriate for emergency sanitation planning globally are also made.

In order to generate the richness of data required, in-depth qualitative interviewing was adopted as the chosen methodology, as opposed to, for example more quantitative techniques such as questionnaires (Rubin and Rubin (1995). Such an approach seeks to build trust and openness through empathy, and recognises that the interviewer is not a neutral actor but a participant in an interviewing relationship, with their emotions and cultural understandings having an impact on the interview (Monaghan and Just 2000). This research therefore borrowed from two main theoretical areas: feminist research and postmodernism. Firstly, feminist research, because of the emphasis on subjective, empathetic, process oriented, inclusive approaches, combined with the flexibility to choose research techniques across boundaries between academic fields (e.g. Lather 1991). Secondly, postmodernism, in recognition that knowledge takes numerous forms and is unique to particular people, therefore a certain methodological self-consciousness is necessary which recognizes that language is an inadequate vehicle for expressing any sort of 'reality' (e.g. Bernard 2006, Hall 1973, Robson 2002).

In order to minimise bias as part of this chosen methodology, or allow for the effects of it where it occurred, reflexivity on the part of the researchers was necessarily an integral activity. This involved the interviewers asking multiple sides of a story and empathizing 
with conflicting points of view, even if those were not shared by the interviewer. In this type of research it is impossible to eliminate bias, but if the researchers are fully aware that they may be biased then they can try and minimise it.

Groups of women and groups of girls were interviewed to enable as many of their opinions as possible to be heard in a short space of time. Women were asked to volunteer for the focus group discussions whilst girls were selected by the Senior Women Teacher in each case. The purpose of the research was explained to the participants, and their consent to participate in the research was sought. Any who did now want to participate left the group at this point, although they could leave at any point during the focus group. No men were present so the women could talk at ease if they wanted to, or remain quiet. No names were recorded so the participants' anonymity was assured. The interviewer sat on the floor with the participants to avoid any feelings of intimidation. The focus group discussions started with a round of introductions, and translation was done by a LWF social worker (for the women) or a Senior Woman Teacher for the school girls. Whilst a discussion guide had been prepared, informal discussion covered the issues in a culturally appropriate way. Discussions were recorded and notes were taken. No full names were recorded, to respect confidentiality.

Issues raised in these discussions were triangulated with other available information such as individual interviews with other key informants. Key informants included teachers, NGO workers, and health professionals. Observations were made in the camps, villages and schools according to a checklist which included a description of the design, the 
function, appearance, smell and items available (soap, water and basins). Following the interviews, the recordings were transcribed and common themes are described in the results section.

Details of the variety of interviews conducted can be found in table 1. Altogether the research includes:

- 10 focus group discussions with up to 45 women each in IDP camps

- 3 focus group discussions with up to 25 women each in villages

- 16 focus group discussions of up to 15 girls aged 9 to 20 in 14 schools, accompanied by a female teacher

- 8 interviews with senior or head teachers

- 9 interviews with health workers

[Insert table 1]

The camps were selected from all parts of the region, and the selected camps varied in size and age. However, it was not possible to select camps on the basis of ethnicity, area of origin of residents, socio-economic status, levels of education or literacy, and hence there is a possibility that the camps were not representative. Although the authors are confident that through data triangulation and attention to matters of bias, accurate data has been gathered, the different culture and language of data gatherers compared to respondents may have resulted in some attitudes and opinions having been lost in translation. These factors may also have affected the girls' and women's willingness to 
express their problems and fears in front of each other, or in front of their teachers. However, these effects were minimised to the extent of not distorting the data presented. It should also be noted that by their nature, focus group discussions can be dominated by the opinions of one or two individuals, and may not reflect the majority view. However, they do allow opinions to be gathered from a lot of women in a short space of time, and can be less intimidating than a face to face interview.

This was a piece of exploratory research into the experiences of girls and women about menstrual management. It is based on the theory that the subjects of the research have real experiences which can be elicited by a sympathetic and sensitive researcher, and those experiences and perceptions deserve to be heard and documented. It is an ontological approach which combines objectivism and realism, and an epistemological approach which is a blend of interpretivism and critical realism.

\section{Results}

In each of the following sections, the three contexts of villages, schools and camps are compared for each of the four menstrual management themes.

Description, demographics, activities

The thirteen IDP camps visited were densely populated with mud-brick or thatch huts situated, on average, less than ten metres apart. Seven or eight people, both male and female, and often only distantly related, lived in each dwelling. Bathing facilities (for washing) and latrines (for urinating and defecating) were communal and generally 
located around the periphery of the camps, but well within sight for security reasons. Each camp had at least one borehole within $200 \mathrm{~m}$ of the edge of the camp.

In villages, mud-brick homesteads were typical. Built with land surrounding them, these were occupied by one family (up to 7 or 8 people) with dividing walls for men and women. Each homestead had its own bathing facility within the compound.

The daily activity of female residents involved caring for children, collecting firewood and water, cooking and farming. These activities were similar in both village and camp life, though more arduous in the camps due to more dependent household members (often orphans) and no formal land to farm.

The average school size in the research region was 581 pupils. Female school attendance decreased with age at all of the schools. For example, at two of the primary schools investigated, the female drop out rate over the first seven years was $75 \%$ and $66 \%$ respectively. At a secondary school, there was a 97\% reduction in numbers from the first to the sixth year and at another secondary school, there was a reduction of $42 \%$ over just one academic year. Early marriage was the most prevalent reason given by the girls for dropout, but lack of money for scholastic and menstrual materials was cited as another reason by girls and teachers in two of the fourteen schools.

\section{Menstrual materials}


Almost all of the women interviewed used cloth from old, worn clothes to absorb their menstrual blood, or more rarely, cloth bought from a health clinic. However, out of the 29 focus group discussions , 17 specifically commented that they found the use of cloth to be ineffective due to poor absorption, discomfort and leakage. The cloth, which lasted anywhere from one to six months depending on age at time of first use as a menstrual cloth, was held in place by a waistband (see figure 2) or, less frequently, by underpants. Some more affluent village women or school girls used disposable sanitary pads with underpants. These cost between $\$ 1$ and $\$ 1.85$ for a packet of 12 pads, but were not available from the markets in Katakwi.

[Insert figure 2]

In camps, there was great difficulty in procuring cloth, and women often had to resort to using rags found outside the home, such as discarded head-cloths used by women carrying water containers from boreholes. Users stated this practice was undesirable and is not practised in the villages where all cloth was sourced from within the home. In four of the schools either cotton cloth or sanitary pads were available to girls in an emergency, but these were bought using government funds. In the other schools, there were insufficient funds for such an emergency service.

'[We use] old clothing, but if we don't have any we take rags that somebody has dropped in the rubbish pit'. Women, Aketa Camp.

'We use old clothes, sometimes we find rags by the borehole.' Women, Amursia Camp.

'[We use] old clothes and if we do not have those we pick them up from the rubbish and wash them.' Women, Ongongoja Camp. 
All women interviewed stated a preference of using well fitting underpants to hold material in place, but these were expensive and difficult to obtain. Older women preferred to use clean, dark coloured cotton cloth which would not show stains, whereas younger women, who had occasionally used disposable pads which they had been given by schools, health clinics or NGOs, expressed a desire to use pads for reasons of comfort, absorption and freedom of movement. To continue using disposable pads, many older girls worked to raise money to pay for them in addition to their scholastic materials. The girls worked in other people's gardens, sold produce in the market or brewed local beer. When a menstrual cloth or disposable pad is no longer useable it is disposed of in a pit latrine, or if no latrine is available, it is buried.

Five of the fourteen schools had received cotton cloth from NGOs. Whilst the cloth was considered effective for their emergency needs, it did not suffice on its own. The girls lacked soap and basins to wash the cloth and tight fitting pants to hold the cloth. However once the cloth had deteriorated and been disposed of, no further cloth was available so girls in camps had to resort to rags again. Another five schools had received sanitary pads from NGOs and teaching staff noted improved school attendance. At one school the supplies were running low and there was no sign of replenishment. At the other schools, the girls reported no problems in the disposal of pads, although the supply of pads had only just started.

\section{Menstrual management facilities}


In order to manage menstruation with dignity, private areas and facilities (soap and buckets) are required for washing and drying cloths in close proximity to latrines or bathing areas. In the camps, there were not enough basins or soap, and they were not able to bathe once a day as they were in the villages.

'We also need more basins, the ones we have now are broken and we have to wash everything in them - our rags, our babies. Everything is put into the same basin'. Women, Palam Camp

Cloths are usually changed up to three times a day. In villages, women wash their used cloth within the homestead bathing facilities using a separate family basin. The cloth is then dried outside in the sun. They feel comfortable doing this because their dwellings are sufficiently separated from each other. However, the situation in camps and at schools is reported as significantly worse.

At all the camps visited the women did not have enough privacy to cope with their menstrual periods hygienically or with dignity. Common problems included broken or absent doors on latrines and bathing shelters, which forced women to wash and change rapidly or in the dark. The cloths were then hung indoors on the eaves of their dwellings, sometimes covered with another cloth to hide it from other family members. The cloths do not dry quickly but women feel that there is no alternative because it is not acceptable to hang their cloths outside in view of other families, especially men and boys.

'Village life was different, we had privacy. We were able to wash and dry the rags outside. We dried the rags on the roof [of the dwelling] or in the bush and we were less exposed'. IDP woman, Amursia Camp. 
In the village we were able to wash and hang the rags anywhere without shame, in the camp that is very difficult'. IDP woman Ngariam Sub-County Camp

In the villages we had freedom and space to dry the rags outside the huts. Here [in the camp] we have no privacy to dry the rags, we are forced to hang them in the house. We also have to wait until evening to wash the rags'. IDP woman, Milmil Camp

A consequence of the poor drying facilities is that women resort to wearing damp cloths. Medical professionals interviewed reported repeated use of damp cloths leads to health problems such as rashes, fungal infections and Urinary Tract Infections (UTIs). Damp cloth is also more uncomfortable to wear and rubs against the skin causing open sores, which are vulnerable to infection. Medical staff at the camps confirmed that numerous women suffer from Candidiasis, a fungal infection that can be caused by poor hygiene. The women rarely seek medical advice for these problems, which are only noticed when they are examined for another medical problem. Health centres can provide free antibiotics to treat UTIs but medication for Candidiasis must be bought from drug stores. This is relatively expensive at $\$ 1.50$ for a typical course of treatment.

In six of the schools where facilities were observed, the facilities were also inadequate and girls were not willing to change their menstrual material whilst at school. Common problems stated included: lack of soap; no water close at hand; no area available for drying cloths; no bathing facilities; and too few latrines. Water was available at all schools but if located away from the latrines the girls had to carry water across the school drawing unwanted attention. The number of latrines relative to girls was also significantly below the government and Sphere (2004) standards. The ratio of girls to facilities (mixed and girls) averaged at 70:1 across the ten schools, compared to 40:1 
(Government of Uganda standards) and 20:1 (Sphere, 2004). Some of the latrines had been destroyed by animals. Some girls who lived close to the school ran home to change their cloth and thus remained in school. Others did not attend school during their menstrual period and thus fell behind academically and increased the likelihood of dropout. Other girls remained in school but did not change until the end of the school day. As a result they ran the risk of smelling, leaking, being in discomfort and getting an infection.

\begin{abstract}
'Most of them [schoolgirls] stay at home. It is very difficult to come to school when they have their menstruation because they don't have the facilities to change their underpants, the sanitary pad they don't have, they don't have money for buying them, so most start using rags which are very difficult to maintain and even to wash. So most of them stay away'. Senior Woman Teacher, Obulengorok Camp School
\end{abstract}

'We would like bags for carrying such things [as menstrual materials] because we just have 'kaveras' (plastic bags) like we use to go to the market, but when we just use 'kaveras' the boys can grab them thinking it is cassava we are bringing from home. We would like bags with locks'. 'Girls at Obulengorok Camp Primary School.

'...we are embarrassed to transport rags to and from school. We have no bags to put them in'. Girls at Adere Primary School.

\title{
Education about menstruation
}

Many menstruation myths can be dispelled through appropriate, targeted education. Some of the myths encountered during this research included:

- A menstruating woman should not go to the groundnut field as this will bring a bad harvest.

- A missed menstrual period indicates HIV/AIDS. 
- Cloths must not be burnt, or discarded where others may find them as this may bring misfortune to the woman.

- If a pad is discarded in a latrine, the girl will not reproduce

The primary route of education about menstrual management is through schools. In all of the schools investigated, girls were taught about menstruation, though the quantity and quality of teaching varied significantly. Topics comprised one or all of the following: personal hygiene, managing menstrual materials and the biological menstrual cycle. The importance of educating girls about menstruation was widely acknowledged by both male and female teachers. Yet despite this, there was a general consensus amongst NGO staff, health staff, government officials, and teachers that girls did not know enough about menstruation and still believed myths. This was confirmed by the basic questions asked by primary and secondary schoolgirls during the focus group discussions. From the Senior Nursing Officer's experience, many girls still did not know: what periods were; why females have them; what can be expected (regularity, extent of bleeding, and what is abnormal); how to cope with period pain; what menstrual materials are effective; and how to manage materials (transporting when soiled, washing and drying, and disposal).

Girls in nine of the ten focus groups that addressed the issue were not prepared for their first period. They did not know what it was and feared it was another sickness. In rural areas and in camps, girls were less aware and more bashful about menstruation. 
Only four of the fourteen schools stated that boys were taught the basics about menstruation including the practicalities involved. In these schools, girls and teachers explained that the incidence of teasing had fallen. However there were still reports of teasing if girls had a problem with menstruation. When asked if they would like a local nurse to come and talk to them about menstruation, the girls generally responded positively. Four schools already had a visiting nurse to undertake medical examinations and talk about health but the nurse did not always talk about menstruation. In eight out of ten schools asked, the older girls spoke to the younger girls about issues of growing up, like menstruation, and it was believed an effective means by which the younger ones could learn. One of these schools had a more formal arrangement, referring to child-tochild teaching. There was no significant difference in educational practises between menstruation between schools attended by IDPs and schools with no IDPs.

Approximately half of the girls were taught about menstruation at home, with no significant difference observed between the camps and the villages. This task fell to the women in the family. The remaining girls learnt about menstruation only at school. The impression from all adult participants in the research was that most parents or guardians do not sufficiently educate their girls about menstruation. Poor menstruation education at home was attributed to poverty and ignorance, as many parents would not have received any education about menstrual management themselves. The situation is compounded by unfamiliarity with modern materials and inability to provide girls with necessities such as menstrual materials, pants, a basin, soap, and sometimes painkillers. In the towns, parents 
were generally more educated and aware of the issues that affected girls' education than in rural areas.

\section{Daily life during menstruation}

The women and girls are very fearful that the 'rags' are obvious to others or that they may loosen and fall. In one group, women described moving and sitting in strategically careful ways in order to 'maintain themselves'.

In the camps more than half of the interviewed women stated that they had had to remain in their homes for some part of their menstrual period because of abdominal pain and shame due to lack of sufficient menstrual material to protect from staining their clothes. At these times neighbours and children help with daily chores such as water collection. This sometimes meant that girls were kept away from school in order to care for the household. Conversely, in the villages women rarely remained indoors during their menstrual period. This was because their rags dried more quickly enabling them to change more frequently and feel more confident about being in public. They also said that neighbours are not near enough to be called on for help.

Teaching staff in eight of the schools reported that girls missed school during their menstruation. The main reasons cited were abdominal pain, fear of teasing and that they would not be able to 'maintain themselves'. According to the teachers interviewed, if girls miss four days a month, they fall behind academically increasing the likelihood of dropout. Of the five schools with good attendance during menstruation, four schools had 
recently received pads from NGOs to give to the girls. There did not seem to be any particular policy targeting schools containing IDPs for this intervention. The fifth school was Kokorio Primary School, serving local village (no IDPs) where the girls interviewed were unusually confident, open and willing to talk about issues on menstruation. They had markedly different experiences and attitudes towards menstruation from their peers in other schools. They never missed school during their menstrual period and they used the latrines to change rags during the school day. They carried their menstrual materials to and from school in black plastic bags and claimed not to be teased or bothered by boys when going to the latrines with the bags; and they were not afraid of staining their clothes. It may be possible to attribute the difference in attitude and behaviour found at Kokorio to one or more of the following:

- The school latrines were clean, and had strong metal doors, with large working locks.

- The girls' latrines were well separated from those of the boys.

- Both boys and girls at Kokorio had received sex-education classes and had talked about 'growing-up' issues in class.

\section{Discussion}

There is a clear and compelling basis for intervention in menstrual hygiene management. Females unable to manage their menstruation feel undignified by the sights, smells, teasing, discomfort and infections that can result. Productive time spent at work and school suffers. 
It was observed that women in the camps faced greater challenges than women in the villages. Specifically, they found it difficult to procure menstrual cloths and they had a lack of privacy to change their cloths and wash and dry them. This latter challenge is a factor of the camps' cramped conditions and inadequate provision of sanitation. The lack of space to dry the cloths has further impacts as it means that women cannot change cloths regularly and are forced to remain in the home, not outside doing productive activities. The use of damp cloths potentially leads to urinary tract and vaginal infections. Attempts to address menstrual management by the NGO working in the camps were hampered by a lack of time, research and capacity. Further research is needed to understand the constraints which prevent appropriate support being made to displaced women and girls.

Preferences for different types of menstrual materials can vary within a community. NGOs typically treated girls and women the same despite differing preferences (girls wanted pads, women cloth) but acted in the best interests of all (by giving cloth) considering the facilities available and financial sustainability.

Disposable pads are still prohibitively expensive. Tearfund (2009) estimated that buying sanitary pads for one woman would cost $10 \%$ of a poor family's monthly income. It is likely that more people will use pads in the future as they become more affordable and popular with women. If they dispose of them down the latrine, consideration needs to be made for the larger pit size required. The impact of disposable pads on the solids accumulation rate in pits is not known and requires further research. In non-emergency 
situations, women are able to dispose of disposable pads with other solid waste, bury them or burn them (Ten 2007, Dasgupta and Sarkar 2008, Dhingra et al 2009, Water Aid 2009, Fernandes 2010, Mahon and Fernandes 2010) but this may not be possible in IDP camps. This situation may be improving with the introduction of Makapads in Uganda. These are locally manufactured pads which sell for around half the price of other brands. They are made from $99 \%$ local materials, with the main raw material being papyrus reeds, which grow abundantly across the country (Ishingoma 2006). However they have been reported as being insufficient for the heaviest menstrual flows (Sommer 2012). They were not available on the market at the time of research.

For improvements to menstrual hygiene to be sustained, the community at large needs to be sensitised to the importance of girls' education and issues like menstruation. Whilst of course women have been managing their menstruation for generations in their villages, living in the camps means they cannot manage their menstruation in the usual way, and hence education about menstruation becomes as important as providing suitable facilities. Menstruation must not remain a taboo subject if women and girls are to manage themselves better and avoid unnecessary health problems, disrupted education and low self-esteem. However, efforts to include menstrual hygiene education in primary schools in Bangladesh were resisted by policy makers as it was seen as against norms and values (Nahar and Ahmed 2006), and development workers in India were worried that introducing the subject could damage relations with the community (Mahon and Fernandes 2010). Menstruation is not only a taboo in Uganda; Ten (2007) describes how menstruation is a taboo across Asia and Africa, and Dhingra et al (2009) and Fernandes 
(2010) describes the restrictions on women in India. If women are embarrassed about their menstruation they will take extreme steps to disguise it, including hiding their menstrual rags so they do not dry properly. Again, this is not exclusive to Uganda, and has been observed in Nepal (Water Aid 2009), Bangladesh (Bharadwaj and Patkar 2004, Ten 2007, Ahmed and Yesmin) and India (Dhingra et al 2009).

Although the schools were all day schools, the girls needed to bathe each time they changed their cloth so bathing facilities are essential. However, they were absent in the schools visited in this study. If female teachers and girls continue to use cloth, bathing shelters are necessary for privacy, personal hygiene and to avoid embarrassment from leaking. The facilities need only be basic structures made out of local materials but must include a system for drainage to prevent stagnant surface water. However, LWF (2006) found that $15 \%$ of schools in Katakwi and Amuria did not have separate stances for boys and girls and that $40 \%$ of school latrines in Katakwi and Amuria Districts did not comply with Government design specifications.

\section{Conclusions and recommendations}

The menstrual hygiene needs of women and school girls have been gravely overlooked in both relief and development programmes forcing them to cope with their menstrual management in any way possible. This has negative impacts on the dignity and mobility of women and school girls. Davis and Lambert (2002) recommend that communities are consulted at all stages in the planning, monitoring and evaluation of a sanitation 
programme in emergency camps. This research has shown that women and girls in the IDP camps of Katakwi were not sufficiently consulted about their menstrual needs, which has been reflected in the poor menstrual management practices they have been forced to adopt.

Simply providing menstrual material is an insufficient way of addressing menstrual management in schools and camps. Explanations are required of how to use and manage the material, and key messages should be regularly reinforced. Menstruation places extra demands on female consumables, so there is also a need for additional tight pants, soap and basins. Furthermore, a sufficient amount of gender sensitive sanitation infrastructure is fundamental in schools and camps, including private, clean and secure latrines and bathing shelters, with a nearby water supply for handwashing and bathing.

An emergency situation can erode the social fabric of communities. As such, particular care is often placed on ensuring effective education and emotional and financial support for those affected. For women and girls, menstrual management education is essential to ensure an understanding of the biology of menstruation, and in particular, how to achieve the best menstrual hygiene and when to seek medical help. Boys should not be excluded from menstrual education as an increase in their understanding helps reduce the embarrassment and exclusion of girls and women during their menstrual period. Parents and carers of children also need to be informed about the importance of teaching girls about menstruation at home, offering emotional and financial support, and providing appropriate sanitation facilities. 
Changes are required to the design of sanitation programmes so that menstrual management of women and girls is effectively addressed. First and foremost consultation is required with school girls, teachers, women and the wider community about menstrual hygiene needs. Menstruation is seen as a taboo subject and must be dealt with sensitively. Cultural perceptions of menstruation and their implications on interventions should not be ignored but understood and catered for appropriately. Stakeholders should be more involved in participatory design and monitoring of the provision of facilities.

It is recommended that national and international emergency response guidelines on menstrual hygiene interventions should promote financially and environmentally sustainable solutions, including:

- Consultation with girls and women regarding their menstrual needs, including what Non Food Items they require and what bathing facilities they would like.

- Training in the use of menstrual materials

- Non Food Items to include tight pants, soap and basins

- Private, clean and secure latrines with water available nearby

- Education of both boys and girls in menstrual biology and hygiene. 


\section{References}

Action by Churches Together. (2003) Emergency Assistance to IDPs in Katakwi District. Geneva.

Adhikan, P., Kadel, B., Dhugel, S. I. and Mandal, A. (2007) 'Knowledge and practice regarding menstrual hygiene in rural adolescent girls in Nepal'. Kathmandu University Medical Journal 5(3): 382-386.

Ahmed, R. and Yesmin K. (2008) 'Menstrual hygiene: breaking the silence'. In Wicken, J., Verhage, J., Sijbesma, C., Da Silva, C. and Ryan, P. (eds) Beyond Construction Use By All, Delft: IRC International Water and Sanitation Centre and London:WaterAid, pp. 283-287.

Anibue, U. U. Aniebue P. N. and Nuankwo T. O. (2009) 'The impact of pre-menarcheal traning on menstrual practices and hygiene of Nigerian school girls'. Pan African Medical Journal 2(9).

Bernard, H.R. (2006). Research methods in Anthropology - Qualitative and Quantitative Approaches. Lanham: AltaMira Press.

Bharadwaj, S. and Patkar, A. (2004) 'Menstrual Hygiene and Management in Developing Countries: Taking Stock'. Mumbai: Junction Social, Social Development Consultants 
Czerwinksi, B. (1996) ‘Adult feminine hygiene practises'. Applied Nursing Research 9(3): 123-129.

Davis J. and Lambert R. (2002) Engineering in Emergencies, Second Edition, London: ITDG Publishing.

Dasgupta, A. and Sarkar, M. (2008) 'Menstrual hygiene: How hygienic is the average adolescent girl', Indian Journal of Community Medicine 33(2): 77-80.

Demba, E., Morison L., van der Loeff, M.S., Awasana, A.A., Gooding, E., Bailey, Mayaud, P. and West, B. (2005) 'Bacterial vaginosis, vaginal flora patterns and vaginal hygiene practices in patients presenting with vaginal discharge syndrome in The Gambia, West Africa'. BMC Infectious Diseases 5 (12).

Deo, D. S. and Ghattargi, C. H. (2005) 'Perceptions and practices regarding menstruations: a comparative study in urban and rural adolescent girls'. Indian Journal of Community Medicine 30(1): 33-34.

Dhingra, R., Kumar A. and Kour M. (2009) 'Knowledge and practices related to menstruation among tribal (Gujjar) adolescent girls'. Studies on Ethno Medicine 3(1): 4348. 
Erulkar, A.S., Abebaw, F., Ambelu, W., Girma, W., Amdemikael, H., mGebreMedhin, B., Legesse, B., Tameru, A., and Teferi, M. (2010), Ethiopia young adult study in seven regions, Addis Ababa: Population Council and New York: UNFPA

Fernandes, M. (2010).'Freedom of mobility: Experiences from villages in the states of Madhya Pradesh and Chattisgarh, India', South Asia Hygiene Practitioners' Workshop, Dhaka, Bangladesh, February 2010

Geiger, A.M. and Foxman, B. (1996) 'Risk Factors for Vulvovaginal Candidiasis: A Case-Control Study among University Students'. Epidemiology 7(2): 182-187.

Gomez, S. (2006) Guidelines for Gender Sensitive Disaster Management, Chang Mai: APWLD

International Displacement Monitoring Centre. (2005) 'Uganda: Relief efforts hampered in one of the world's worst internal displacement crises'. 12 December 2005. Geneva: IDMC

Hall, E. T. (1973) The Silent Language. New York: Random House

International Federation of Red Cross and Red Crescent Societies (2010) A practical guide to gender-sensitive approaches for disaster management. Geneva: IFRCRC

Ishingoma, J. 2006 'Makapads: Makerere University makes affordable sanitary pads'. Dec 16 2006, Kampala: UG pulse 
Kamaljit, K. , Balwinder, A., Gurmeet, K.S. and Neki, N.S. (2012) 'Social beliefs and practices associated with menstrual hygiene among adolescent girls of Amritsar, Punjab, India'. Journal International Medical Sciences Academy 25(2): 69-70

Kirk, J., and Sommer, M., (2006) 'Menstruation and body awareness: linking girls' health with girls' education' In Special on gender and health, Amsterdam: Royal Tropical Institute (KIT), pp, 1-22

Lal, S., Nawaz, J., and Raza, S. (2007) 'Screened sanitation units - The Pakistan earthquake'. Waterlines 25(3): 28-29

Lather, P. (1991) Getting smart: feminist research and pedagogy with/in the postmodern. New York: Routledge.

Leegaard, M. (1984) 'The Incidence of Candida Albicans in the Vagina of "Healthy Young Women": How often do they have symptoms? Possible etiological factors'. Acta Obstetricia et Gynecologica Scandinavica 63(1): 85-89

LWF. (2006) Katakwi AIDS Project January 2006 - December 2008. Katakwi: LWF

Mahon T. and Fernandes M. (2010) 'Menstrual hygiene in South Asia: a neglected issue for WASH (water, sanitation and hygiene) programmes', Gender and Development Journal 18(1): 99-113 
McMahon, S.A., Winch, P.J., Caruso, B.A., Ogutu, E.A., Ochari, I.A. and Rheingans, R.D. (2011) "“The girl with her period is the one to hang her head" Reflections on menstrual management among schoolgirls in rural Kenya', BMC International Health and Human Rights 11 (1): 7

Monaghan, J. and Just, P. (2000) Social \& cultural anthropology, New York: Oxford University Press Inc,.

Nahar, Q. and Ahmed R., 2006 'Addressing the special needs of girls: challenges in school'. SACOSAN II, Islamabad, Pakistan

Narayan, K. A., Srinivasa D. K. Pelto, P. J. and Veeramal S. (2001) 'Puberty rituals, reproductive knowledge and health of adolescent schoolgirls in South Asia' Pacific Population Journal. 16(2): 225-238

Neuman, W. L. (1997) Social Research Methods: Qualitative and Quantitative Approaches, Boston: Allyn \& Bacon.

Prüss-Ustün, A., Bos, R., Gore, F. and Bartram, J. (2008) Safe Water, Better Health: Costs, Benefits and Sustainability of Interventions to Protect and Promote Health. Geneva: World Health Organization 
Rubin, H. J. and Rubin, I. S. (1995) Qualitative Interviewing: The Art of Hearing Data. Thousand Oaks: Sage Publications, Inc.

Raralio, E.N. and Ebo, E. (2009) Gender Integration in Disaster Management: Philippines, Singapore: APEC

Robson, C. (2002) Real World Research: A Resource for Social Scientists and Practitioner-researchers, Oxford: Blackwell.

Shanbhag, D., Shilpa, R., D'Souza, N., Josephine, P., Singh, J. and Goud, B.R, (2012) 'Perceptions regarding menstruation and practices during menstrual cycles among high school going adolescent girls in resource limited settings around Bangalore city, Karnataka, India' International Journal of Collaborative Research on Internal Medicine and Public Health 4(7): 1353-1362

Singh, M,M,, Devi, R., Garg, S. and Mehra, M. 2001 'Effectiveness of syndromic approach in management of reproductive tract infections in women'. Indian J Med Sci. 55: 209-14.

Sommer, M. (2010) 'Putting menstrual hygiene management on to the school water and sanitation agenda'. Waterlines 29(4): 268-278 
Sommer, M. (2012) 'Menstrual hygiene management in humanitarian emergencies: Gaps and recommendations' 31(1-2): 83-104

Sphere Project. (2011) Humanitarian Charter and Minimum Standards in Disaster Response. Geneva: Sphere Project

Tchoudomoriva, k., Mardh, P., Kallings, I., Nilsson, S., and Hellberg, D. (1998) 'History, clinical findings, sexual behavior and hygiene habits in women with and without recurrent episodes of urinary symptoms'. Acta Obstet Gynecol Scand. 77: 654-659.

Thakre, S.B., Thakre, S.S., Reddy, M., Rathi, N., Pathak, K. and Ughade, S. (2011) Menstrual hygiene: Knowledge and practice among adolescent school girls of Saoner, Nagpur District, Journal of Clinical and Diagnostic Research 5(5): 1027-1033

Tearfund. (2009) 'Gender and sanitation: breaking taboos, improving lives'. Teddington: Tearfund

Ten V. T. A. (2007) Menstrual hygiene: a neglected condition for the achievement of several millennium development goals, Zoetermeer: Europe External Policy Advisors.

United Nations. (2008) The Millennium Development Goals Report 2008, New York: United Nations 
UN High Commissioner for Refugees. (2001) UNHCR's Commitments to Refugee

Women, 12 December 2001, Geneva: UNHCR

WaterAid. (2005) 'Sanitation Provision in Benishangul-Gumuz Region State (BGRS)

Schools: Girls and Women's Experiences. Addis Ababa: Water Aid.

WaterAid. (2009) 'Is menstrual hygiene an issue for adolescent schoolgirls?'

Kathmandu: Water Aid. 


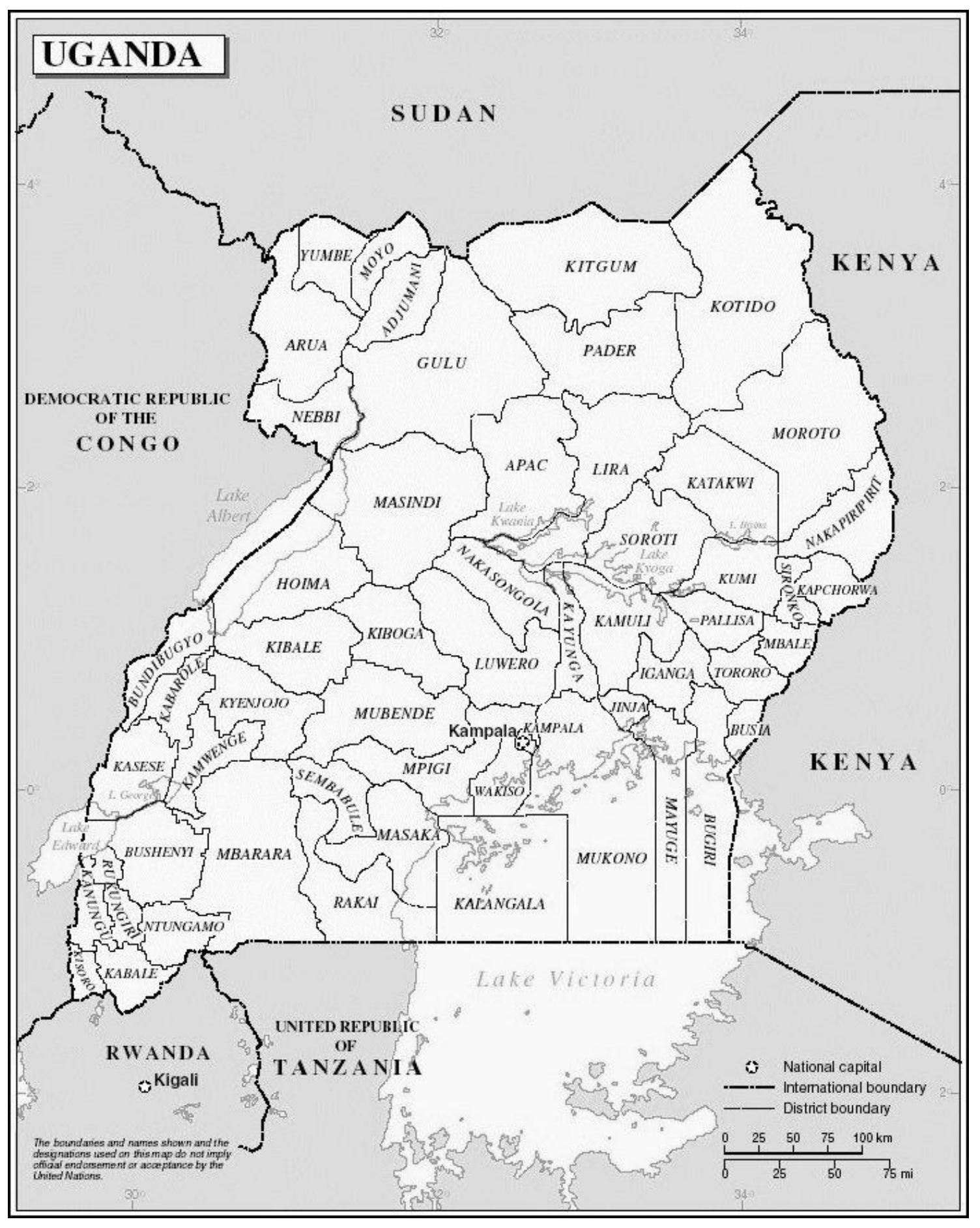

Figure 1 The location of the study area, Katakwi District, within Uganda. Note that in 2007 (after the field study was completed) the district was split into two, Katakwi and Amuria. 


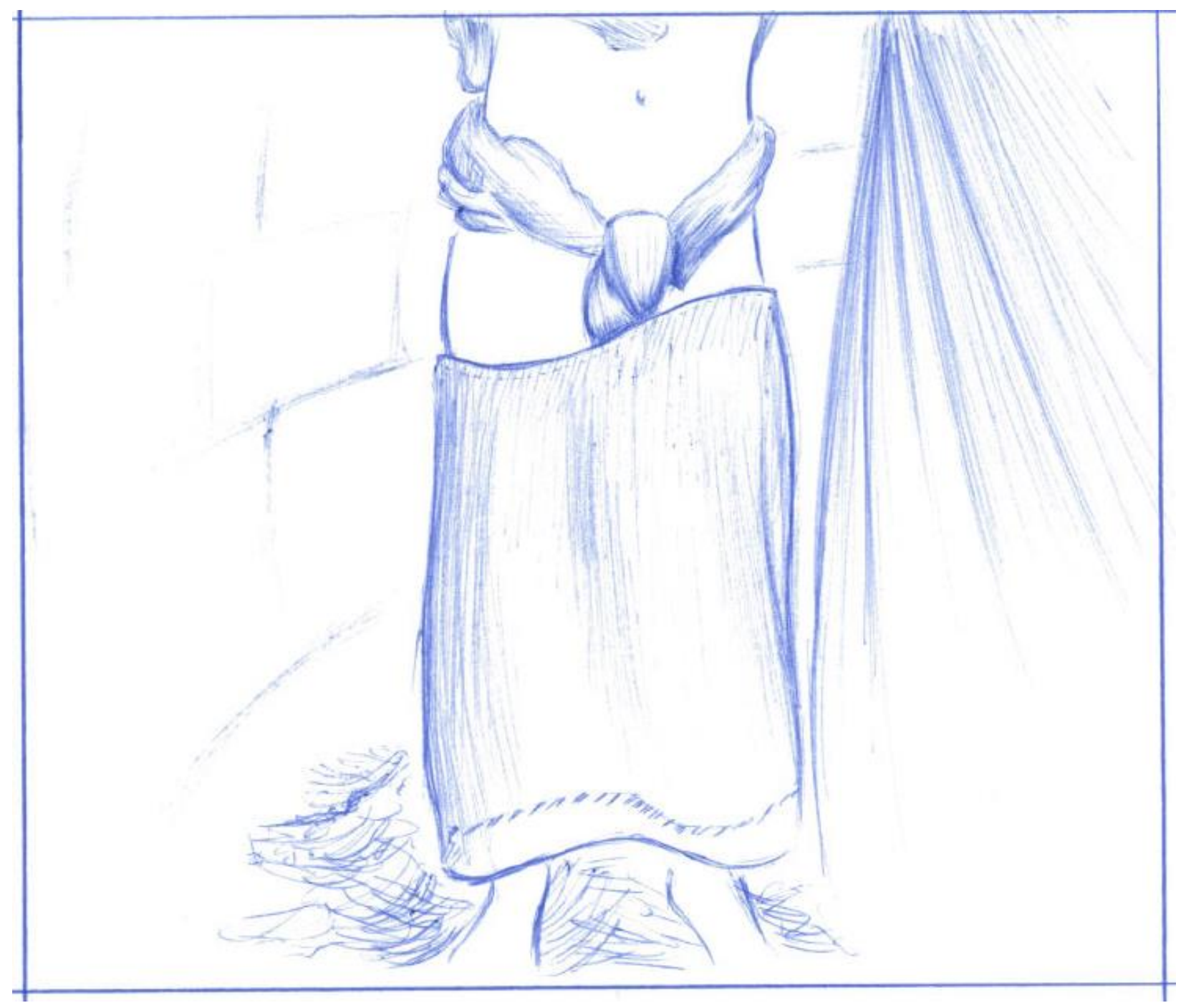

Figure 2 A menstrual cloth tied with a waistband. Sketch by Ross Tierney based on a photograph taken during fieldwork. 
Table 1 Summary of interviews conducted. Where details are missing where it was not possible to collect the data

\begin{tabular}{|c|c|c|}
\hline $\begin{array}{l}\text { Location and age (where } \\
\text { known) }\end{array}$ & $\begin{array}{l}\text { Number of } \\
\text { people }\end{array}$ & Interview details \\
\hline Milmil IDP camp (5 years) & 1165 & Focus group discussion with 30 women \\
\hline Aketa IDP camp & 2720 & $\begin{array}{l}\text { Focus group discussion with } 40 \text { women } \\
\text { Semi-structured interviews with two } \\
\text { nurses and a midwife }\end{array}$ \\
\hline Obulengorok IDP camp & 2401 & Focus group discussion with 45 women \\
\hline Ongongoja IDP camp & 472 & Focus group discussion with 28 women \\
\hline Amursia IDP camp (3 years) & 1695 & Focus group discussion with 40 women \\
\hline $\begin{array}{l}\text { Ogolokwar IDP camp ( } 2 \\
\text { years) }\end{array}$ & & Focus group discussion \\
\hline $\begin{array}{l}\text { Ngariam Sub County Camp } \\
\text { (5 years) }\end{array}$ & & Focus group discussion \\
\hline Palam IDP camp & & Focus group discussion \\
\hline $\begin{array}{l}\text { Kipinyang IDP camp (6 } \\
\text { months) }\end{array}$ & 590 & Focus group discussion with 20 women \\
\hline Ocwiin IDP camp & & No interviews \\
\hline Oliangoi IDP camp & & Focus group discussion with 20 women \\
\hline Oriau IDP camp & & No interviews \\
\hline Obalanga IDP camp & & No interviews \\
\hline
\end{tabular}




\begin{tabular}{|c|c|c|}
\hline Katakwi Township Primary & 623 & $\begin{array}{l}2 \text { focus group discussions with } 12 \text { girls } \\
\text { aged } 12 \text { to } 14 \text { and } 8 \text { girls aged } 14-16 \text { from } \\
\text { both the town and the IDP camps } \\
\text { Semi-structured interview with } \\
\text { headmistress }\end{array}$ \\
\hline Aakum Primary & 911 & $\begin{array}{l}\text { Focus group discussion with } 10 \text { girls } \\
\text { aged 9-16 from the IDP camps } \\
\text { Semi-structured interview with } \\
\text { headmaster }\end{array}$ \\
\hline Ocwiin Primary & 282 & $\begin{array}{l}\text { Focus group discussion with } 10 \text { girls } \\
\text { aged 9-15 from the IDP camps } \\
\text { Semi-structured interview with } \\
\text { headmaster }\end{array}$ \\
\hline Angodingod Primary & 512 & $\begin{array}{l}\text { Focus group discussion with } 15 \text { girls } \\
\text { aged 13-16 from a village } \\
\text { Semi-structured interview with } \\
\text { headmaster and senior teachers }\end{array}$ \\
\hline Acumet Secondary & 386 & $\begin{array}{l}\text { Focus group discussion with } 15 \text { girls } \\
\text { aged 14-18 from the IDP camps } \\
\text { Semi-structured interview with } \\
\text { headmaster }\end{array}$ \\
\hline Apuuton Primary & & $\begin{array}{l}\text { Focus group discussion with } 10 \text { girls } \\
\text { aged } 14-16 \text { from the town and the IDP }\end{array}$ \\
\hline
\end{tabular}




\begin{tabular}{|c|c|c|}
\hline & & camps \\
\hline Labira Secondary & & $\begin{array}{l}\text { Focus group discussion with } 5 \text { girls aged } \\
15-20 \text { from the IDP camps }\end{array}$ \\
\hline Amuria Secondary & 809 & $\begin{array}{l}\text { Focus group discussion with } 10 \text { girls } \\
\text { aged 14-18 from the town and the IDP } \\
\text { camps } \\
\text { Semi-structured interview with deputy } \\
\text { head }\end{array}$ \\
\hline Oriau Primary & 476 & $\begin{array}{l}\text { Focus group discussion with } 10 \text { girls } \\
\text { aged } 14-16 \text { from the IDP camps } \\
\text { Semi-structured interview with } \\
\text { headmaster }\end{array}$ \\
\hline Toroma Girls Primary & 648 & $\begin{array}{l}2 \text { focus group discussions, each with ten } \\
\text { girls aged 11-18 and 13-16 respectively } \\
\text { from a village. } \\
\text { Semi-structured interview with senior } \\
\text { female teacher }\end{array}$ \\
\hline $\begin{array}{l}\text { Obulengorok Camp Primary } \\
\text { School }\end{array}$ & & $\begin{array}{l}\text { Focus group discussion with } 8 \text { girls, } \\
\text { average age } 16 \text { from IDP camps } \\
\text { Semi-structured interview with senior } \\
\text { female teacher }\end{array}$ \\
\hline Adere Primary School & & $\begin{array}{l}\text { Focus group discussion with } 8 \text { girls from } \\
\text { IDP camps }\end{array}$ \\
\hline
\end{tabular}




\begin{tabular}{|c|c|}
\hline Atoroma Primary School & $\begin{array}{l}\text { Focus group discussion with } \\
\text { headmistress, senior female teacher and } \\
\text { girls }\end{array}$ \\
\hline Kokorio Primary School & $\begin{array}{l}\text { Focus group discussion with } 8 \text { girls aged } \\
15-16 \text { from villages }\end{array}$ \\
\hline Atete village & Semi-structured interview with female \\
\hline Akurawo village & Focus group discussion \\
\hline Kelim village & Focus group discussion with 25 women \\
\hline Okwalo village & Focus group discussion with women \\
\hline $\begin{array}{l}\text { Katawki District Health } \\
\text { Centre }\end{array}$ & Semi-structured interview with midwife \\
\hline Toromo Medical Unit & Semi-structured interview with doctor \\
\hline Amuria Health Clinic & $\begin{array}{l}\text { Semi-structured interview with medical } \\
\text { officer, midwife and nurse }\end{array}$ \\
\hline Asamuk Health Centre & $\begin{array}{l}\text { Focus group discussion with ante-natal } \\
\text { group } \\
\text { Semi-structured interview with midwife }\end{array}$ \\
\hline
\end{tabular}

